\title{
Commercialization Methods of a New Product/service in ICT Industry: Case of a Science \& Technology Park
}

\author{
Alireza Aslani, Hossein Eftekhari, Mahdi Hamidi, Bahareh Nabavi \\ Faculty of New Sciences and Technology, University of Tehran, Tehran, Iran; \\ Corresponding author: alireza.aslani@ut.ac.ir
}

\begin{abstract}
Purpose: Commercialization is a step toward new products/services development. Due to high rate of product/service failure in ICT industry, the purpose of this paper is to study and evaluate commercialization methods implemented by companies that operate within ICT industry at the Science and Technology Park of University of Tehran.

Design/Methodology/Approach: The methodology of this study is of field research type. After examining commercialization methods presented in the literature and confirming methods found by the discipline elite, structured interviews were conducted addressed managers and experts of ICT companies.

Results: Three methods of "joint research contracts", "exhibitions" and "spin-offs" are among the most common commercialization methods used by companies.

Conclusion: Due to uncertainties that exist in ICT industry, companies should consider different strategies in order to develop successful products and services. Finally, specific policies are determined to implement each commercialization method in knowledge-based companies.
\end{abstract}

Keywords: innovation, commercialization, ICT, science and technology park

\section{Introduction}

According to dictionary definition, commercialization means applying business methods to achieve profit for a new technology/product/service. In fact, selection of the best commercialization strategy is the central part of successful diffusion of innovation that can increase the market share and the profit of the organizations. Thereby, due to the importance of commercialization, certain institutions are working to speed up the diffusion process and technology transfer of new technologies/products/services. For example, the number of technology transfer institution have been increased from 25 to 200 during 1980-2002 period in the U.S. to decrease the failure of new products/ technologies/ services (Kaylson, 2004).

Due to the importance of the commercialization of new technologies/ products/ services, the purpose of this research is to identify the most important commercialization methods in ICT industry. ICT industry is a high-tech industry with high level of uncertainty and fast changes that bring about high rate of failure for companies. But which method can bring more success in the process of new technologies/products/services commercialization for the ICT companies?

To respond to the question that, which method can perform well in commercializing knowledge-based companies' technological products and services, subjects such as diffusion of innovation, technology, and commercialization are reviewed. After that, the main challenges of commercialization are investigated, in particular in ICT companies. Then, the important methods of commercialization are examined in different industries. Moreover, the important methods of commercialization of a successful technology/ product/ service are identified in ICT industry based on survey and observation.

The results will help managers and policy makers in ICT industry to select successful methods in order to predict the failure or success of their products/ services. Finally, some recommendations are presented to implement each method. 


\section{Literature review}

\subsection{Diffusion of innovation and technol- ogy}

Companies seek to increase their competitive advantages. While maintaining their current customers via different tactics, they also try to attract new customers in the current or new markets. To achieve this, they attempt to implement different strategies such as new products/services development. However, the successful implementation of such strategies is not easy and involves different challenges.

Diffusion of technology and innovation is discussed from two points of view in the literature; innovation and technology transfer. While utilization of new technologies usually follows the S-curve during time in the innovative view, different businesses with various aims and capabilities propagate technologies in different times based on technology transfer view (Probit model; Geroski, 2000). Due to the importance of the diffusion of innovations in society and beneficiary groups, commercialization of new products/services is an important concept for diffusion of innovation in that it enables a product/service to obtain its desirable position in the market.

\subsection{Commercialization of new products/ services}

There is a variety of definitions for commercialization. Commercialization can be "applying business methodology to exploit or profit." According to Cambridge Dictionary (2014), commercialization means organizing something to gain profit. Indeed, commercialization is "presentation of a product or service to market for earning profit" or "process of turning something into commercial activity". In the literature of innovation, Dayan (2004) defines commercialization as presenting a new product/service to the market. APCTT (2005) emphasizes that commercialization is a set of activities: obtaining and growing the ideas, development of the technologies based on research, building a prototype, expansion of the developed technologies, developing new processes or optimizing the existing, presenting new products/services to the market, creating sale conditions and development of new infrastructures for new technologies/products/services. From another viewpoint, commercialization is the process of transferring knowledge and technology from research centers to the industries and new businesses (Aghajani and Yazdanpanah, 2005).

\subsection{Importance of commercialization of new products/services}

Knowledge and technology commercialization have a long history in the literature of innovation and business. In the past, limited technologies and knowledge gained from sci- entific studies were presented to the markets and became commercial. However, knowledge and technology commercialization began by interactions between university and industry since 1862 (Karlsson, 2004).

Emphasizing knowledge and technology transfer from universities to industries leads to development and implementation of various transfer-based mechanisms such as creation of technology transfer and entrepreneurship offices at universities, creation of incubation centers, and science and technology parks such as Silicon Valley. Based on this view, the process of commercialization can be divided in two steps: planning and execution.

Suitable model and related strategies should be identified and determined for successful commercialization in the planning phase. After that, commercialization process is accomplished according to identified models with respect to concerning strategies (execution step; Kotler, Saunders and Wong, 1999).

Despite the importance of commercialization in diffusion and promotion of innovation, there are challenges during the process, in particular for ICT companies. Important challenges are reviewed in following.

\subsection{Important challenges of commercial- ization}

Despite the importance of small companies in the economy and regional development, the failure rate is quite high in such companies in first years from their creation. According to the reports from small businesses in the U.S., more than 50 percent of small businesses faced failure in first year, and 70 percent may be eliminated in their first 5 years (Elyasi, Chitsaz and Gerami, 2010).

This failure rate is much higher in developing countries. For instance, our investigations show that failure rates for the same time span are 60 percent and 90 percent in Iran due to important reasons such as financial expectations, communicative problems, need for technical and financial support, cultural differences between university and industry, and lack of entrepreneurship spirit at universities. Indeed, cultural conflicts, lack of technology offices, financial problems, human resource problems, bureaucratic structure, and conflicts with partners and stakeholders are other challenges (Siegel, Waldman and Link, 2003; Kirihata, 2007).

According to Plewa (2005), technology expansion, knowledge development, publications, offering royalty, subjects about human resources, gaining profit, gaining fund for future research, achieving public budgets are the main barriers of commercialization and failure of new companies. To lead the commercialization process to success, there are different methods and strategies that can be implemented for companies. These methods help companies decline risks of new technology/product/service failures. 


\subsection{Important methods of commercializa- tion}

According to Mitchell (1990), commercialization methods are approaches to transfer technology like participation and also licensing. Some examples include: licensing, collaboration of two or more companies with subscribing technological abilities, relying on self-knowledge and resource development of a third company with limited lifetime, human resource exchange and employment by receiver company as agent, outsourcing and contractors (Chiesa \& Manzini, 1998).

To select the suitable commercialization method, there are criteria such as minimum costs, maximum attraction of technology, maximum transfer time, maximum access to the market, and keeping up with technological evolutions (Hassan pour et. al, 2012). These methods can be categorized based on different approaches:

- licensing and using intellectual properties and presenting consultative services to private and public sectors (Pourezzat et al. 2010)

- Development of spin-offs. (Lockett and Wright, 2005).

For example, development of spin-offs is an important entrepreneurial method for commercialization of academic technologies/ products/services. However, using each of the aforesaid methods depends on factors such as nature of new product, service, technology, market conditions and University policies. In fact, knowledge and technology developed at universities, regardless to its commercialization capabilities, are transferable to the industry and pri- vate or public sector organizations. According to Bozeman (2000), eight different connective ways to the process of technology transfer are: (1) Published articles or papers, (2) patents, (3) Licensing, (4) Attracting technology, (5) Informal methods, (6) Human resource exchange, (7) Presenting technology at the place, (8) Development of generative companies.

Furthermore, presenting consultative services, holding meetings with managers of industries, development of efficient companies based on technology transfer from universities, and joint research with industry are other methods of technology/ knowledge transfer mentioned in various studies (Landry et al., 2007). In addition, Gans and Stern (2003) introduced set-up method for commercialization shown in the Table1.

Studies show that the commercialization methods have their own priority in each industry (Gans and Stern, 2003; Kascha and Dowling, 2008). This means that while a commercialization method may be useful in one industry, it may be not be successful in another. This depends on the nature and complexity of the industry. Therefore, some countries such as U.S. and South Korea have especial organizations for technology transfer and commercialization to study and give professional counsel on the process of successful transfer. These organizations are especially practical for technological commercialization at its primary stages of diffusion and adoption of new technologies/ products/services. They use horizontal and vertical methods of commercialization (Iskoskov and Chernova, 2013). Overall, the researchers of the current work summarize important methods of commercialization based on Table 2 .

Table 1: Methods of commercialization

\begin{tabular}{|c|c|c|c|c|c|c|}
\hline \multicolumn{7}{|c|}{ Methods of commercialization presented by Gans and Stem (2003) } \\
Commercialization strategies & Sale and \\
complete exit \\
\hline \multicolumn{2}{|c|}{ Exploitation Licensing }
\end{tabular}

Table 2: Summing up commercialization methods

\begin{tabular}{|c|c|c|}
\hline $\begin{array}{c}\text { commercialization } \\
\text { method }\end{array}$ & Explanation & References \\
\hline Licensing & $\begin{array}{c}\text { A company obtains the right to exploit a } \\
\text { particular technology }\end{array}$ & $\begin{array}{c}\text { (Gans \& Stern, 2003) } \\
\text { (Yadollahi Farsi and Kalathaee, 2012) } \\
\text { (Mozaffari and Shamsi 2011) }\end{array}$ \\
\hline Strategic Alliances & $\begin{array}{c}\text { A company subscribes it's technologic } \\
\text { resources without being available any stocks to } \\
\text { achieve common goal of technologic innova- } \\
\text { tion through it }\end{array}$ & $\begin{array}{c}\text { (Chiesa and Manzini, R, 1998; Bogers } \\
\text { and Maarse, 2012; } \\
\text { Yadollahi Farsi and Kalathaee, 2012) }\end{array}$ \\
\hline
\end{tabular}


Table 2: Summing up commercialization methods (continued)

\begin{tabular}{|c|c|c|}
\hline Joint Venture & $\begin{array}{l}\text { A company enacts to collective investment by } \\
\text { participation of others, with a specified goal of } \\
\text { technologic innovation, } \\
\text { and a new company will be created. }\end{array}$ & $\begin{array}{c}\text { (Chiesa \& Manzini, 2007; Arabi, 1998; } \\
\text { Yadollahi Farsi and Kalathaee, 2012) }\end{array}$ \\
\hline $\begin{array}{l}\text { Development of new com- } \\
\text { panies based on University } \\
\text { technologies (Spin-off) }\end{array}$ & $\begin{array}{l}\text { Companies which are developed by side of } \\
\text { researching centers or University and } \\
\text { commercialize their technology innovation }\end{array}$ & $\begin{array}{c}\text { (Chiea, andManzini , 1998; Pourezzat } \\
\text { et.al., 2010) }\end{array}$ \\
\hline Exhibitions & $\begin{array}{l}\text { Holding conferences and book fairs, publishing } \\
\text { articles and international fairs of commerce and } \\
\text { industry. }\end{array}$ & $\begin{array}{c}\text { (Arabi, 2007; Chernova and Iskoskov, } \\
\text { 2013) }\end{array}$ \\
\hline $\begin{array}{l}\text { Joint research contracts } \\
\text { (projects) }\end{array}$ & $\begin{array}{l}\text { Two companies enact to bind a contract to- } \\
\text { wards cooperation in grounds of research and } \\
\text { expansion or development of a new product or } \\
\text { service }\end{array}$ & $\begin{array}{l}\text { (Shah Miri and Salami, 2011; ;Arabi, } \\
\text { 2007; Amir Khani and Isfandiari, 2012; } \\
\text { Mozaffari and Shamsi, 2011) }\end{array}$ \\
\hline $\begin{array}{l}\text { Offering consultative Ser- } \\
\text { vices }\end{array}$ & $\begin{array}{l}\text { Consultative services usually are services and } \\
\text { in formations that are required in product or } \\
\text { materials. Commonly, those services are of- } \\
\text { fered by and productive units which have nec- } \\
\text { essary and enough experiences in the domain }\end{array}$ & $\begin{array}{c}\text { (Hodavand, 2006; Pourezzat et.al. 2010; } \\
\text { Mozaffari and Shamsi, 2011) }\end{array}$ \\
\hline $\begin{array}{l}\text { Technology transfer net- } \\
\text { works and innovation } \\
\text { networks }\end{array}$ & $\begin{array}{l}\text { A company develops a net of infra organi- } \\
\text { zational relationships to prevent lagging in a } \\
\text { technologic domain }\end{array}$ & (Chernova and Iskoskov, 2013) \\
\hline Venture capital & $\begin{array}{l}\text { Angels like to invest for commercialization of } \\
\text { new products/services }\end{array}$ & (Chernova and Iskokov, 2013) \\
\hline
\end{tabular}

Table 3: Research steps

\begin{tabular}{|c|c|}
\hline Stage 1 & Literature review \\
\hline Stage 2 & Summarizing the literature and recognizing the commercialization methods \\
\hline Stage 3 & Interview with experts of commercialization and innovation to confirm the methods \\
\hline Stage 4 & $\begin{array}{r}\text { Structured interview and completed questionnaires to consider applying methods in the } \\
\text { companies for successful new products/services }\end{array}$ \\
\hline Stage 5 & Investigate the results of the questionnaire and statistical analysis (research finding) \\
\hline Stage 6 & Conclusions and suggestions \\
\hline
\end{tabular}




\section{Methodology}

Tthe goal of this research is to identify main methods of successful commercialization for new products/services in information and communication technology (ICT) industry. Due to the importance of commercialization of new products/services, as well as the high rate of product/service failure in ICT industry, identification of suitable commercialization methods is necessary to decline the rate of failures and increase the success rate of the new products/ services. Therefore, an applied research was designed to identify the most important commercialization methods. In the Following, the research steps are shown (Table 3 previous page).

The commercialization methods, and in particular those that can be applied to ICT companies, were extracted by literature review and collecting experts' opinions (Table 2). To identify the most important commercialization methods in ICT industry, a survey and two observations were implemented for the case companies. The statistical population of this research is start-ups, spin-offs, and knowledge-based companies having products/ services in ICT industry in Iran. The ICT companies located at the science and technology park (STP) of University of Tehran (UT) were selected as the sample of this research. The STP of the UT is the most important STP in the Middle East and stands among top ten STPs in Asia. The ICT companies located here are successful examples of innovative companies in ICT industry in Iran. They have offered more than 70 successful products/services. However, they have faced many failures during the new product/services designs and distribution to the market.

An open-response questionnaire was designed and distributed to identify the process and methods of commercialization in ICT industry. In this study, in order to ensure validity in design and use of questionnaires, a preliminary consultation with experts was made. For this purpose, 5 questionnaires were distributed among a group of experts and defects of questions were identified. The questionnaire was distributed among scientists and the necessary explanations were provided for each company. In order to promote the goals of the study, individuals with relevant education, management and executive experience in the field of ICT were selected. In the following the case study (Science and Technology Park of University of Tehran) is introduced.

\subsection{Science and technology park of Uni- versity of Tehran}

The science and technology park (STP) of University of Tehran (UT) was established in 2001. The major goal of the park is to help expansion of pre-incubators, incubators, and knowledge-based businesses with emphasis on the UT capabilities. Based on the statistics published in August 2014, there were 231 companies/pre-incubators located at STP of UT with 270 percent growth compared with 2008 (62 companies). These companies/pre-incubators are divided into two main categories: Technology companies and incubators (43.5\% of total in 2008 and $60.4 \%$ in 2014) and pre-incubators $(56.6 \%$ of total in 2008 and $39.4 \%$ in 2014). On the other hand, around 1800 job opportunities have been created (in 2014) by companies located in STP of UT, around five times more than 2008. More than 30 companies, incubators, and pre-incubators are doing their business at STP of UT with annual turnover of more than 10 million U.S. dollars.

\subsection{Data collection}

Around two hundred companies are working at STP of UT divided into three groups; mature companies (40\%), incubators $(40 \%)$, and pre-incubators (20\%). Mature companies are active in the fields of energy, ICT, medicine, etc. Around $45 \%$ (35) of the mature companies and incubators work in the field of ICT. To complete this research, 25 companies were interviewed (Table 4). The respondents are managers and the experts working in R\&D and marketing units of the companies. During the process of data gathering, researchers have tried to observe the structure and process of each commercialization method for each new product/service in terms of its successfulness.

Table 4: Information of selected companies

\begin{tabular}{|c|c|c|c|c|c|c|c|}
\hline $\begin{array}{l}\text { Number of } \\
\text { companies } \\
\text { located in } \\
\text { Park }\end{array}$ & $\begin{array}{c}\text { Type of } \\
\text { companies } \\
\text { located in Park }\end{array}$ & $\begin{array}{c}\text { Number of } \\
\text { selected } \\
\text { companies for the } \\
\text { research }\end{array}$ & $\begin{array}{l}\text { Number of } \\
\text { interviewed } \\
\text { companies }\end{array}$ & \multicolumn{2}{|c|}{$\begin{array}{c}\text { Number of Interviewees } \\
\text { according to the type of } \\
\text { education degree }\end{array}$} & \multicolumn{2}{|c|}{$\begin{array}{c}\text { Number of } \\
\text { Interviewees } \\
\text { according to their age }\end{array}$} \\
\hline 90 & $\begin{array}{c}\text { Mature } \\
\text { companies }\end{array}$ & \multirow{3}{*}{35} & \multirow{3}{*}{25} & Bachelor & 9 & $20-30$ & 7 \\
\hline 40 & Incubators & & & Master & 13 & $30-40$ & 15 \\
\hline 25 & Pre-Incubators & & & Doctorate & 3 & $40-50$ & 3 \\
\hline
\end{tabular}




\section{Research findings}

Figure 1 shows the main result of the research. It shows the share of each commercialization method for successful products/services in ICT industry. To do so, we extracted the frequency of the commercialization methods used in the case study. For example, it could be said that $40 \%$ of companies have used licensing model for commercialization of new products/services. This result is obtained by dividing the number of companies using the licensing model on total of 25 companies. For other models results are shown in Figure 1.

As Figure 1 shows, the joint research contracts method is the most applied commercialization method among knowledge-based companies. The percent 85 means new products/services that used this method were successful in the Market. After that, presenting the new products/services in the exhibitions in order to find the customers, and spin-offs are important methods based on the findings.

\section{Discussion and conclusion}

The commercialization concepts are divided into two approaches: launching new products/services to the market to gain profit and process of turning a technology into the market, and development of profiting conditions for a technology. However, the success methods for commercialization used by companies are important for both approaches. A company cannot be successful if it wants to diffuse and promote its products/services without commercialization methods. The reason is the complexity of products/services along with complex markets that causes high level of competition and uncertainty. Thus, cooperation with other companies is important. This occurs via knowledge and experience exchanges which sometimes occur by the staff exchanges between two companies. Indeed, small/medium companies may not have commercialization abilities, but they can use the experience and capabilities of their large peers.

In this research we tried to answer the research question: which method can bring more success in the process of new technologies/products/services commercialization for the ICT companies? The results show that three methods of "joint research contracts", "exhibitions", and "spin-offs" have the most efficiency towards successful commercialization of new products/services among ICT companies. We chose the most effective commercialization methods that have an average of over $50 \%$ (Figure 1). So, this does not mean that other methods cannot be effective in the successful commercialization of new products/ services. For any industry, methods may vary.

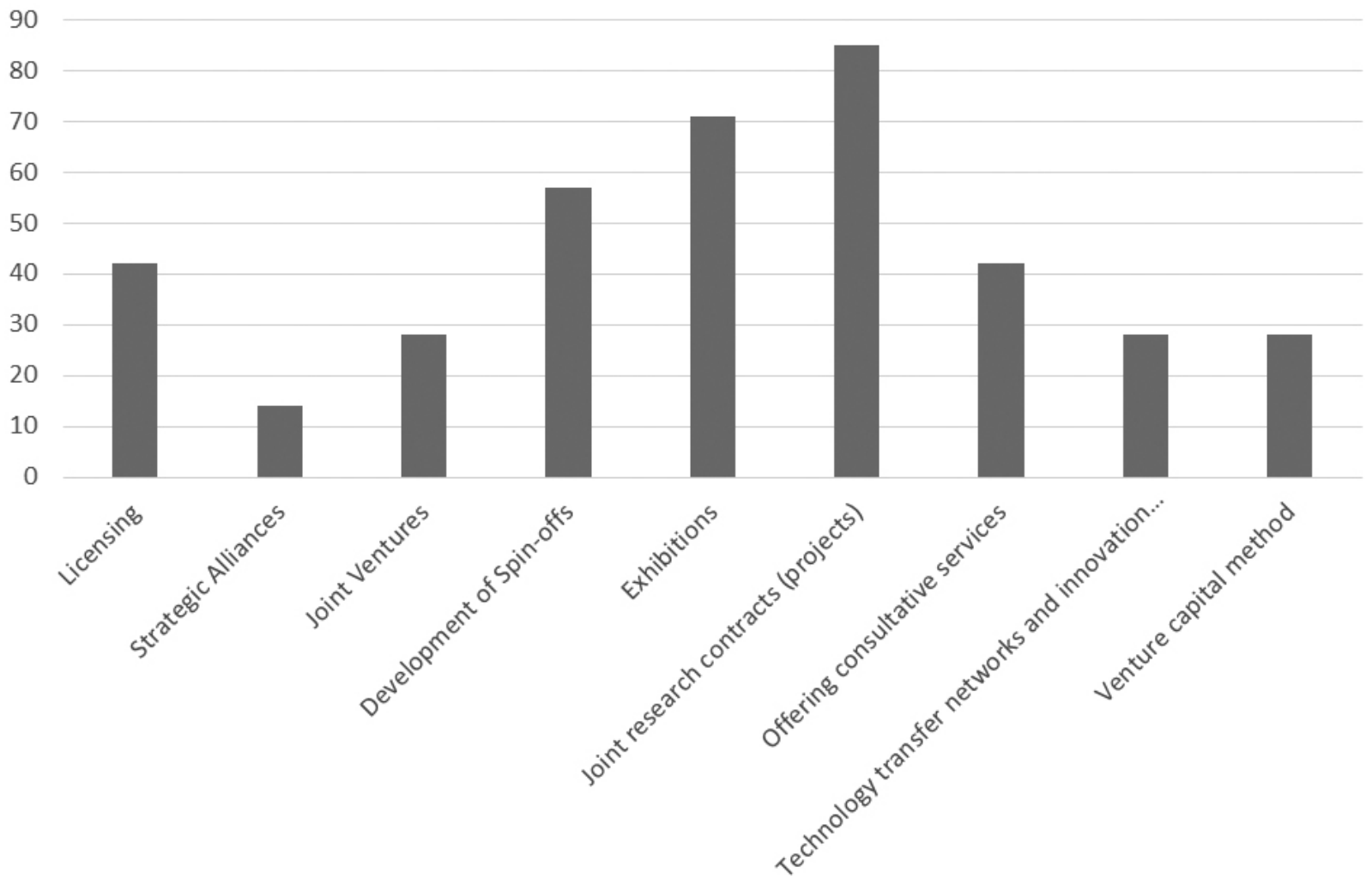

Figure 1: Share of each commercialization method for successful product/services 
Joint research contracts: The first is joint contracts between companies. Several methods have been introduced in the literature for this type of collaboration, including merging, joint venture, etc. These contracts can overcome the shortfall of not having access to large and appropriate markets for small companies. To reach a joint contract, benefiting from the staff, whose role is to introduce companies' achievements to other companies with larger market, can be fairly noticeable. Also, inviting owners and managers of larger companies to pay a visit to current achievements and future plans of small/medium companies, can make a significant contribution. Joining inter-companies' network, is another strategy that if noticed, can bring remarkable results. These inter-company networks are suitable places for presenting various achievements in an integrated knowledge based environment, which is especially considerable in terms of getting to know about other companies' activities and as a result, foster more collaboration between them.

Exhibitions: As mentioned earlier, holding exhibitions to show the companies' achievements is of real importance for companies. To realize this, small companies working in common fields (here ICT), can demonstrate their achievements in these exhibitions. By assembling, these companies can get to know each other's activities, exchange new ideas and also facilitate the not-so-easy process of holding an exhibition, which may not be affordable for a single company.

Spin-offs: To facilitate the creation of these companies, there is a need for close collaboration between universities and small companies. Allocating sufficient financial resources to universities to run these companies can be a good strategy to help them grow. Utilizing potential human resources at universities such as students and professors involved in this field can be of crucial importance in order to improve the quality of spin-offs' activities. Indeed, spinoffs are also important for successful commercialization of product/services. They transfer the achievements of university researches to industry and create wealth and social welfare. Founders of such companies are in contact with university staffs and faculties and are mainly based on the technologies developed and evaluated at universities.

Licensing and Offering Consultative Services; as mentioned earlier, these models can also be considered as efficient commercialization models of new technologies/ products/ services for ICT companies, but in this research we chose commercialization methods that have average of over $50 \%$ according to experts. Nevertheless, it seems that a significant number of companies use these two methods for commercialization.

\section{Limitations and suggestions for future research}

Limitations of this research are mainly associated with the statistical population. Since companies in ICT industry are geographically dispersed, companies located at Science and Technology Park of University of Tehran are a sample of these companies which are working in specific conditions. Therefore other companies located in different parks or independent companies may have different results.

Our research shows that the literature of the commercialization still needs to be developed. We believe this research is the first attempt to analyze the commercialization methods of an industry. The commercialization methods of successful products/services at other industries such as oil and gas, medicine, and aerospace are interesting subjects which are suggested by the authors.

\section{Literature}

Aghajani, H.A. \& Yazdanpanah, E. (2005). Consideration of effective factors on technology transfer from university to industry at universities. Fourth conference on Iran's technology management, Tehran, (in Persian). Assembly of Iran's Technology Management. Retrieved from http://www.dl-iramot.ir/DocDetail.as$\mathrm{px}$ ? itemid $=51$.

Amir Khani, A. \& Isfandiari, M. (2012). Methods for effective transfer of technology. Roshde-Fannavari, $8(31), 2-11$.

Arabi, A. (1998). Technology transfer methods. Tadbir Tehran, (in Persian). 10(179), 61-64.

Bozeman, B. (2000). Technology transfer and public policy; a review of research and theory, Research policy, 29(4-5), 627-55, http://dx.doi.org/10.1016/S00487333(99)00093-1

Chiesa, V. \& Manzini, R. (1998). Organizing for technology collaborations: a managerial perspective, $R \& D$ management, 28(3): 199-212, http://dx.doi. org/10.1111/1467-9310.00096

Elyasi, M., Chitsaz, G., \& Gerami, A. (2010). Identification of effective inter - organizational factors on performance of beginner companies. New economy and commerce seasonal paper, Aghah, (in Persian), No, 21 $\& 22,27-48$.

Gans, J. S., \& Stern, S. (2003). The product market and the market for ideas: Commercialization strategies for technology entrepreneurs. Research Policy, 32(2), 333350, http://dx.doi.org/10.1016/S0048-7333(02)00103$\underline{8}$

Geroski, P.A. (2000), Models of technology diffusion, Research Policy, 29, 603-625, http://dx.doi.org/10.1016/ S0048-7333(99)00092-X

Hassan pour, M. GolAfshani, D. Gholami, R., \& Keshavarzi, Sh. (2012). Consideration of effective factors 
and their inter inter-relationships on technology commercialization success in Islamic Azad University, Ali Abade - Katool (in Persian). National conference on knowledge - based businesses management and entrepreneurship. Ali Abade Katool. Iran. Retrieved from http://www.civilica.com

Hodavand, M. (2006). Technology transfer agreements. Tadbir, 7(167), 25-32.

Iskoskov, O. M. \& Chernova, V. D. (2013). Methods for Commercializing the Results of the Innovation Project. Middle-East Journal of Scientific Research, 13(5), 670-674.

KayLson, M. (2004). Commercialization of research results in United States: An overview of federal and academic technology transfer. Swedish Institute for Growth Policy Studies, Embassy of Sweden, Washington, DC. Elanders Gotab, Stockholm.

Kascha, S., \& Dowling, M. (2008). Commercialization strategies of young biotechnology firms: An empirical analysis of the U.S. industry. Research Policy, 37(10), 1765-1777, http://dx.doi.org/10.1016/j.respol.2008.08.005

Kirihata, T. (2007). Critical success factors in the commercialization process of intellectual property by new technology based firms in Japan. The Kyoto Economic Review, 76 (2), 241-249.

Kotler, P., Saunders J. \& Wong, V. (1999). Principles of Marketing. The Second European Edition, London: Prentice-Hall.

Landry, R., Amara, N., \& Ouimet, M. (2007). Determinants of knowledge transfer evidence from Canadian University researchers in natural sciences and engineering, Journal of Technology transfer, 32(6), 561592, http://dx.doi.org/10.1007/s10961-006-0017-5

Lockett, A. \& Wright, M. (2005). Resources, capabilities, risk capital and the creation of University spin-out companies, Research policy. 34(7), 1043-57, http://dx. doi.org/10.1016/j.respol.2005.05.006

Maarse, J. H., \& Bogers, M. (2012). An Integrative Model for Technology-Driven Innovation and External Technology Commercialization. In C. de Pablos Heredero, \& D. López (Eds.), Open innovation at Firms and Public Administrations: Technologies for Value Creation. (pp. 59-78).

Mitchell, W. (1990). Using academic technology: Transfer methods and licensing incidence in the commercialization of American diagnostic imaging equipment research, 1954-1988. Research Policy 20(3), 203-216.

Mozaffari, A., \& Shamsi, L. (2011). Methods and approaches to commercialization of university research, case study: University of Tabriz. Science and Technology Policy, 3(4), 15-28.

Plewa, C. (2005). Differences in perceived benefits from university-industry relationships. In ANZMAC. Conference: Business Interaction, Relationships and
Networks. Available from http://www.anzmac.org/ conference archive $/ 2005 / \mathrm{cd}$-site/pdfs/7-Business-Interaction-Rel/7-Plewa.pdf

Pourezzat, A., Gholipour, A., \& Nadir Khanloo, S. (2010). Identification and prioritizing effective factors in knowledge commercialization at universities. Entrepreneurial expansion. 2(7), 35-66.

Shah Miri, F. Salami, R. (2011). Factors affecting technology transfer through foreign direct investment, case study: plastics industry. Roshde-Fannavari, 7(27): 2733.

Siegel, D. S., Waldman, D. A., \& Link, A. N. (2003). Assessing the impact of organizational practices on the relative productivity of university technology transfer offices: an exploratory a study. Research poli$c y, 32$ (2): 27-48, http://dx.doi.org/10.1016/S00487333(01)00196-2

Yadollahi Farsi, J. Kalathaee, Z. (2012). Commercialization of technological innovation strategy, based on the theory of transaction cost economics. (In Persian). First International Conference on Management and Innovation. Tehran. Iran. Available from http://www. civilica.com.

Alireza Aslani is an Assistant Professor of the University of Tehran, Iran. He is also a project researcher at the University of Vaasa, Finland. His priorities for research are Technology Management, Science and Technology Policy Making, and System Dynamics.

Hossein Eftekhari is a Master of Science student in the field of Technology Management at the University of Tehran, Iran. His research interests are Technology and Innovation Management and Commercialization of Technologies. He has published different articles in the field of Technology Management.

Mahdi Hamidi is a Master of Science student in the field of Technology Management at the University of Tehran, Iran. His research priorities are Technology Management and Science Park Studies.

Bahareh Nabavi is a Master of Science student in the field of Technology Management at the University of Tehran, Iran. Her research interests are Technology and Innovation Management and Commercialization of Technologies. 